\title{
Patterns of haemodynamic alteration during left ventricular ischaemia in man Relation to angiographic extent of coronary artery disease $^{1}$
}

\author{
ROBERT ARNOLD JOHNSON, LEONARD M. ZIR, RICHARD W. HARPER, \\ ROBERT C. LEINBACH, ADOLPH M. HUTTER, JUN, GERALD M. POHOST, \\ PETER C. BLOCK, AND HERMAN K. GOLD \\ From the Department of Medicine, Harvard Medical School and Massachusetts General Hospital, Boston, \\ Massachusetts, USA
}

SUMMARY Haemodynamic changes produced by rapid atrial pacing ( 60 patients, 52 of whom developed angina) or in association with spontaneous angina ( 32 patients) were measured in 92 patients with angiographic coronary artery disease. The extent of coronary artery disease was scored by the jeopardy score system (range 0 to 12). The haemodynamic changes induced by ischaemia occurred in 3 patterns: pattern $\mathrm{I}$, no change in filling pressure or in mean systemic arterial pressure; pattern II, a rise in filling pressure and a rise in mean systemic arterial pressure; pattern III, a rise in filling pressure, but no significant change or a fall in mean systemic arterial pressure. In patients who had a pattern II or a pattern III response to ischaemia, the change in mean systemic arterial pressure was linearly related to the corresponding change in cardiac output. The likelihood of a patient showing a given pattern of ischaemiainduced haemodynamic change was related to the extent of coronary artery disease: of 22 patients with jeopardy scores of 2 or 4,91 per cent exhibited pattern I, 9 per cent pattern II, and none pattern III; of 39 patients with jeopardy scores of 6 or 8,40 per cent exhibited pattern I, 22 per cent pattern II, and 38 per cent pattern III; of 31 patients with jeopardy scores of 10 or 12, 12 per cent exhibited pattern I, 10 per cent pattern II, and 78 per cent pattern III $(P<0.01)$. Among the 54 patients in whom serial cardiac output determinations were available, a decline of the left ventricular function curve during ischaemia was demonstrable in 8 per cent of those with a pattern I response, in 54 per cent of those with a pattern II response, and in 90 per cent of those with a pattern III response $(P<0.01)$. The pattern of response was unrelated to resting angiographic left ventricular ejection fraction, whether ST segments became elevated or depressed, or whether ischaemia was pacing-induced or spontaneous. These results suggest that the haemodynamic response to ischaemia is determined by the fraction of the left ventricle that becomes dysfunctional during ischaemia.

Left ventricular ischaemia accompanying spontaneous angina, exercise-induced angina, and angina induced by rapid atrial pacing has been shown to be associated in some patients with an acute rise in left ventricular filling pressure, which may precede, accompany, or follow the onset of chest pain (Müller and Rørvik, 1958; Parker et al., 1969; Barry et al.,

${ }^{1}$ This work was supported in part by NHLB Ischemia SCOR Grant.

Received for publication 19 June 1978
1976). A rise in systemic arterial blood pressure is also an accompaniment of angina in some patients (Roughgarden and Newman, 1966; Littler et al., 1973). The extent and pattern of haemodynamic alteration during ischaemia varies from patient to patient, however. Not all patients undergoing haemodynamic monitoring during angina have shown changes in left ventricular filling pressure (Cannom et al., 1974; Lecerof, 1974), and, in some patients, systemic blood pressure has not changed or has even fallen (Cohen et al., 1965; Thomson and Kelemen, 1975). The determinants of the 
haemodynamic response to left ventricular ischaemia are unknown.

The goal of the present study is to examine the relation between the angiographic extent of coronary artery disease and the haemodynamic changes occurring with ischaemia and, moreover, to assess whether this relation is modified by the state of resting left ventricular function.

\section{Methods}

\section{PATIENTS}

The study population, 97 patients, consists of 2 separate groups. In the first group, 65 patients, rapid atrial pacing was performed as part of the cardiac catheterisation procedure. These patients all had a history of recurrent chest pain and had been referred for coronary angiography. In the second group, 32 patients with recurrent angina at rest, haemodynamic and electrocardiographic measurements were recorded during episodes of spontaneous angina. Thirty of the patients with recurrent spontaneous angina at rest underwent electrocardiographic and haemodynamic monitoring in our coronary care unit as part of the clinical management of unstable angina, and 2 patients had electrocardiographic and haemodynamic measurements recorded during an episode of spontaneous angina in the cardiac catheterisation laboratory.

\section{HAEMODYNAMIC AND ELECTROCARDIO- GRAPHIC MEASUREMENTS}

\section{(1) Pacing study group}

The cardiologist who referred the patients for catheterisation often had specifically requested that the pacing study be performed for clinical purposes; in all other cases the patients were asked for informed consent to perform an atrial pacing study as part of the cardiac catheterisation procedure.

Propranolol and isosorbide dinitrate were withheld on the day of the procedure until cardiac catheterisation was completed. Systemic arterial blood pressure was measured by means of a radial artery cannula. A temporary pacing electrode was positioned to achieve high right atrial pacing. Left ventricular pressures or pulmonary artery pressures were recorded by means of saline-filled catheters. Left ventricular end-diastolic pressure was measured at the nadir of the post-A pressure just before the rapid upstroke of the left ventricular systolic pressure; when identification was difficult, the enddiastolic pressure was assumed to correspond to the peak of the electrocardiographic $R$ wave. Left ventricular stroke work (joules) was defined as [stroke volume] $\times$ [mean arterial pressure-left ventricular filling pressure]. Cardiac output determinations were performed in duplicate by an indicator dilution method (indocyanine green injection in right atrium, sampling from radial artery).

The pacing procedure was carried out before angiographic procedures. Resting measurements of left ventricular filling pressure (measured as left ventricular end-diastolic pressure in 59 patients and as pulmonary wedge pressure in 6 patients), mean systemic arterial pressure, cardiac output, and the electrocardiogram (leads III and V4) were recorded. Atrial pacing was then begun 10 to 20 beats/min higher than the patient's resting heart rate, and the pacing rate was increased in increments of 10 beats/min for one minute each until either angina occurred, atrioventricular block developed, or until a rate of $150 / \mathrm{min}$ was reached (a few patients were paced up to as high as 172 beats $/ \mathrm{min}$ ). The highest pacing rate was maintained for 2 minutes whereupon left ventricular filling pressure, mean systemic arterial pressure, electrocardiogram, and cardiac output determinations were recorded, and, subsequently, the pacemaker was turned off. At the offset of pacing, the left ventricular filling pressure was continuously recorded for approximately 20 beats. Three minutes after pacing was discontinued, left ventricular filling pressure, mean systemic arterial pressure, electrocardiogram, and cardiac output measurements were repeated.

The change in mean systemic arterial pressure, change in cardiac output, and change in stroke volume produced by pacing were calculated by comparing values measured at the highest pacing rate with corresponding values measured in the baseline state. The baseline values were taken either as those measured before pacing or as those measured 3 minutes after pacing, whichever gave the smallest differences compared with values at the highest pacing rate. The baseline values were defined in this way because the institution of pacing in itself sometimes resulted in fluctuations of the mean systemic arterial pressure, apparently because of the patient's attendant anxiety that bore no relation to whether or not ischaemia subsequently developed.

The change in the left ventricular filling pressure produced by pacing is defined as the difference between the baseline left ventricular filling pressure and the left ventricular filling pressure at the offset of pacing (average of the second to the eleventh post-pacing beats), unless ventricular function curves are being referred to (see below).

\section{(2) Spontaneous angina group}

Thirty patients with unstable angina had had balloon-tipped pulmonary artery catheters and 
radial artery cannulae inserted in the coronary care unit to facilitate their clinical management. Angina occurred while the patients were resting in bed and while many were receiving varying combinations of propranolol, sublingual or oral isosorbide dinitrate, and cutaneous glyceryl trinitrate paste. In addition, 6 patients were undergoing intra-aortic counterpulsation at the time that angina occurred. Left ventricular filling pressure (pulmonary wedge pressure) and mean systemic arterial pressure were recorded during the patient's subjective complaint of chest pain, but before the administration of glyceryl trinitrate, and were compared with measurements made before pain. Cardiac output was determined before and during angina in 13 patients (indocyanine green or thermal dilution; variability in duplicate determinations of cardiac output by thermal dilution $10 \%$ ). Pulmonary artery and systemic blood pressures were recorded continuously while haemodynamic monitoring was performed. Pre-angina cardiac output determinations were made during a pain-free interval that was remote from administration of glyceryl trinitrate while the patient was on the same therapeutic regimen as that present at the time of angina. Angiographic procedures were performed during the same hospital admission. In no case was myocardial infarction known to occur between the time of the spontaneous angina episode when haemodynamic measurements were made and the time of subsequent angiographic procedures. An additional 2 patients had episodes of spontaneous angina in the catheterisation laboratory; left ventricular end-diastolic pressure and mean systemic arterial pressure during angina were compared with their pre-angina values.

Haemodynamic and electrocardiographic data for a single angina episode per patient are reported. Haemodynamic data surrounding only one episode of angina were available in 29 patients; in the other 3 patients, the pressure data that correspond to the episode during which cardiac output determinations were available were chosen as representative.

\section{DEFINITION OF ISCHAEMIA-INDUCED DECLINE IN VENTRICULAR FUNCTION CURVE}

In the present study, the left ventricular filling pressure and cardiac output were measured together at two points: a baseline state, when left ventricular ischaemia was absent by clinical and electrocardiographic criteria, and during rapid pacing or spontaneous angina, when the degree of ischaemia was to be assessed. Depression of the ventricular function curve during pacing or during spontaneous angina is defined as either a fall in stroke work at an un- changed or higher ventricular filling pressure or as no change in stroke work when the left ventricular filling pressure rises. When ventricular function curves were assessed in pacing-induced ischaemia, the change in the left ventricular filling pressure was measured as the difference between baseline left ventricular filling pressure and the left ventricular filling pressure at the highest pacing rate.

\section{ANGIOGRAPHIC DATA}

All 97 patients underwent selective coronary angiography. All angiograms were reviewed by one observer. The coronary circulation was considered as 6 arterial segments. Each arteriogram was assigned a score, termed the jeopardy score (Dash et al., 1977), which expresses how many of the 6 segments are jeopardised, directly or indirectly, by significant proximal obstruction. The 6 arterial segments and the principle of the jeopardy score are illustrated in Fig. 1. Two points are counted for each segment jeopardised. Thus, the jeopardy score ranged from 0 (a patient with no significant coronary lesions) to

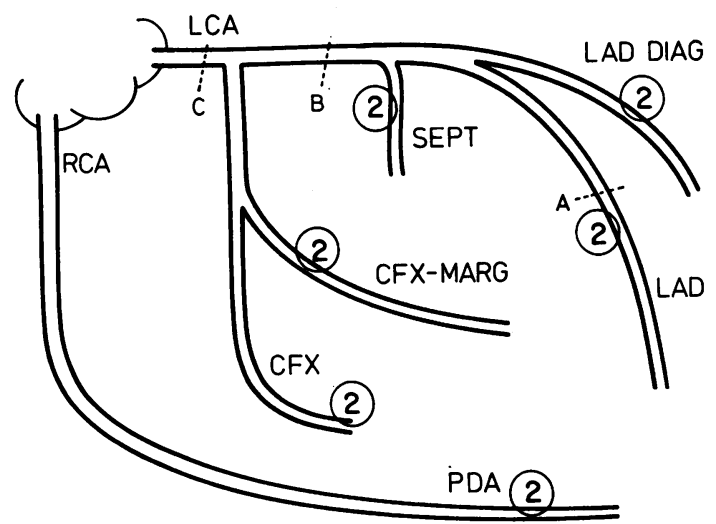

Fig. 1 The jeopardy score system as a semiquantitative measure of extent of left ventricular involvement by coronary artery disease. The coronary circulation is considered as 6 arterial segments (each of which is designated by the number 2 in the figure). Each segment involved, directly or indirectly (by a lesion proximal to its origin), counts 2 points. For example: patients with single lesions located at points $A, B$, or $C$ in the figure would have jeopardy scores of 2,6 , and 10, respectively; a patient with 2 lesions, 1 at point $A$ and 1 at point $C$, would have a jeopardy score of 10. RCA, right coronary artery; $L C A$, left coronary artery; LAD DIAG, major (largest) diagonal branch of left anterior descending artery; SEPT, major septal perforating artery; $L A D$, left anterior descending artery beyond the major diagonal and septal branches; CFX-MARG, major marginal branch of the left circumflex artery; CFX, left circumflex artery beyond the major marginal branch; $P D A$, posterior descending coronary artery. 
Table 1 Heart rate change and electrocardiographic changes during pacing

\begin{tabular}{|c|c|c|c|c|c|c|c|c|}
\hline \multirow[t]{4}{*}{ Geopardy score } & \multicolumn{6}{|c|}{ No. of patients } & \multicolumn{2}{|c|}{$\begin{array}{l}\text { Maximum paced } \\
\text { heart rate (beats/min) }\end{array}$} \\
\hline & \multirow[t]{3}{*}{ Total } & \multirow{3}{*}{$\begin{array}{l}\text { Developing angina } \\
\text { with pacing }\end{array}$} & \multicolumn{4}{|c|}{ Electrocardiographic changes } & \multirow{3}{*}{ Range } & \multirow{3}{*}{ Mean } \\
\hline & & & \multicolumn{3}{|c|}{$S T$ depression $(V 4)^{\star}$} & \multirow[t]{2}{*}{ Othert } & & \\
\hline & & & $1 / 2-1 \mathrm{~mm}$ & $1-2 \mathrm{~mm}$ & $>2 \mathrm{~mm}$ & & & \\
\hline $\begin{array}{l}0 \text { (normal coronary arteries) } \\
2 \\
4 \\
6 \\
8 \\
10 \\
12\end{array}$ & $\begin{array}{r}5 \\
9 \\
10 \\
12 \\
11 \\
11 \\
7\end{array}$ & $\begin{array}{r}1 \\
6 \\
8 \\
12 \\
10 \\
10 \\
6\end{array}$ & $\begin{array}{l}0 \\
2 \\
1 \\
1 \\
0 \\
1 \\
1\end{array}$ & $\begin{array}{l}0 \\
1 \\
3 \\
4 \\
5 \\
5 \\
1\end{array}$ & $\begin{array}{l}0 \\
0 \\
0 \\
3 \\
5 \\
2 \\
4\end{array}$ & $\begin{array}{l}0 \\
0 \\
0 \\
4 \\
0 \\
0 \\
1\end{array}$ & $\begin{array}{r}95-150 \\
120-160 \\
115-150 \\
90-170 \\
90-172 \\
90-150 \\
100-146\end{array}$ & $\begin{array}{l}131 \pm 11 \ddagger \\
133 \pm 6 \\
134 \pm 4 \\
125 \pm 7 \\
116 \pm 8 \\
125 \pm 6 \\
122 \pm 7\end{array}$ \\
\hline
\end{tabular}

* Horizontally depressed or downsloping ST segments.

Intraventricular conduction change or ST segment elevation in the area of an old myocardial infarction.

$\ddagger$ In Tables and throughout the text, \pm refers to standard error of the mean.

12 (a patient with all 6 segments jeopardised). Significant stenosis was considered as diameter reduction of 50 per cent or more. Significant stenoses are not differentiated from complete occlusions in the jeopardy score system-lesions are counted, or not, on an all-or-none basis. If there was left coronary artery dominance, the 2 points allotted to the posterior descending artery were assigned to the left circumflex artery rather than to the right coronary artery.

Cine left ventriculography was performed in 91 patients. The right anterior oblique ventriculogram was used for purposes of this study. Left ventricular ejection fraction (left ventricular stroke volume/left ventricular end-diastolic volume) was calculated by the modified area-length method as applied to singleplane cine ventriculograms (Kasser and Kennedy, 1969).

\section{STATISTICAL ANALYSIS}

Proportions of patient groups with the occurrence of comparable events were analysed by Fisher's exact test or by the $\chi^{2}$ test. The relation of change in mean systemic arterial pressure to change in cardiac output was examined by linear regression analysis.

\section{Results}

In the group of 65 pacing study patients, $5 \mathrm{had}$ angiographically normal coronary arteries ( 4 without evidence of structural heart disease and 1 with a remote myocardial infarction) and $60 \mathrm{had}$ coronary artery disease ( $\geqslant 50 \%$ diameter reduction) involving at least one coronary artery. Of the latter, 19 had 1-vessel disease, 19 had 2-vessel disease, and 22 had 3-vessel disease; 5 had significant narrowing of the main left coronary artery. All of the spontaneous angina patients had coronary artery disease: 10 had 1-vessel disease, 6 had 2-vessel disease, and 16 had 3-vessel disease. Four spontaneous angina patients had significant narrowing of the main left coronary artery.

\section{HEART RATE AND ELECTROCARDIOGRAPHIC} ABNORMALITIES

Of the 60 patients with coronary artery disease who underwent atrial pacing, 52 reported angina during pacing (Table 1). The highest pacing rates achieved are shown in Table 1. Pacing rates did not significantly differ among jeopardy score subgroups. The fraction of patients developing electrocardiographic abnormalities with pacing was related to the angiographic extent of coronary artery disease (Table 1). Electrocardiographic abnormalities occurred in only 7 of 19 patients (37\%) with jeopardy scores of 2 or 4 , compared with 22 of 23 patients $(96 \%)$ with jeopardy scores of 6 or 8 , and 15 of 18 patients $(83 \%)$ with jeopardy scores of 10 or $12(P<0.01)$.

Heart rate changes associated with chest pain in the 32 patients with spontaneous angina ranged from -15 to +32 beats/min and did not differ among jeopardy score subgroups (mean heart rate change $5,0,9,2,12$, and 8 beats/min in jeopardy score subgroups $2,4,6,8,10$, and 12 , respectively). Electrocardiographic abnormalities occurred in 22 of the 24 patients in whom electrocardiograms were recorded during angina, including 7 patients who developed transient ST segment elevations. The latter patients all had significant atherosclerotic coronary disease, by angiographic criteria, in the coronary artery supplying the area of the ventricle corresponding to the site of electrocardiographic abnormality. In the 24 patients who did have an electrocardiogram recorded during angina, the tracing was available for review in only a few; therefore, electrocardiographic descriptions are taken from the daily progress notes in the medical 
record and data are provided only with regard to whether changes occurred or not.

\section{HAEMODYNAMIC CHANGES}

Left ventricular filling pressure at rest did not differ among jeopardy score subgroups: $11 \pm 1,13 \pm 2$, $12 \pm 1,12 \pm 2,11 \pm 2,10 \pm 2 \mathrm{mmHg}$ in jeopardy score subgroups $2,4,6,8,10$, and 12 , respectivelypacing study and spontaneous angina patients combined.

The change in left ventricular filling pressure in pacing patients is measured as the difference between the left ventricular filling pressure at baseline and the left ventricular filling pressure at the offset of pacing, so that changes in left ventricular filling pressures produced by ischaemia are more nearly comparable in pacing patients and in patients having spontaneous angina. For purposes of comparison of jeopardy score subgroups, a change in left ventricular filling pressures was judged to be significant if it exceeded an arbitrary threshold value: a rise in the left ventricular end-diastolic pressure of $7 \mathrm{mmHg}$, chosen because it was the largest change in left ventricular end-diastolic pressure that occurred in patients with angiographically normal coronary arteries, or a rise in pulmonary wedge pressure of $3 \mathrm{mmHg}$. A change in mean systemic arterial pressure was judged to be significant if it exceeded $\pm 15 \mathrm{mmHg}$, a value that was chosen because it is the largest change in the mean systemic arterial pressure that occurred in the patients with normal coronary arteries who were paced, as well as being approximately the value of the change in mean systemic arterial pressure in those patients who had a rise in left ventricular filling pressure which separated patients with a rise in cardiac output from those with a fall in cardiac output (see below).

The changes in left ventricular filling pressure and in mean systemic arterial pressure occurring as a consequence of rapid atrial pacing or accompanying spontaneous angina may be summarised by grouping them into 3 patterns. In pattern I, left ventricular filling pressure and mean systemic arterial pressure did not change significantly; in pattern II, left ventricular filling pressure rose, and a rise in the mean systemic arterial pressure (exceeding $15 \mathrm{mmHg}$ ) occurred; in pattern III, left ventricular filling pressure rose, but mean systemic arterial pressure did not rise significantly or fall. Only 2 patients who did not have a rise in left ventricular filling pressure had a rise in mean systemic arterial pressure exceeding $15 \mathrm{mmHg}$; these 2 patients are considered as having a pattern I response. All patients who did not have coronary artery disease exhibited a pattern I response. Ninety-one per cent of patients with a limited extent of coronary artery disease (jeopardy scores of 2 or 4) exhibited pattern I; an approximately equal fraction of patients with jeopardy scores of 6 or 8 developed each of the three patterns; and 78 per cent of patients with the largest extent of coronary artery disease (jeopardy scores of 10 or 12) exhibited pattern III $(\mathrm{P}<0.01)$ (Fig. 2).

The distribution of patients with regard to the pattern of haemodynamic response within jeopardy score subgroups cannot be explained by differences in the prevalence of propranolol administration or in the prevalence of intra-aortic counterpulsation among the jeopardy score subgroups. Sixty-eight per cent, 69 per cent, and 74 per cent of patients with jeopardy scores of 2 or 4,6 or 8 , and 10 or 12, respectively, were taking propranolol. One patient with a jeopardy score of 2,1 patient with a jeopardy score of 6,1 patient with a jeopardy score of 8 , 2 patients with a jeopardy score of 10 , and 1 patient with a jeopardy score of 12 were undergoing intraaortic counterpulsation at the time of angina.

The distribution of patients with regard to the pattern of haemodynamic response within jeopardy score subgroups is not influenced by whether ischaemia is spontaneous or pacing-induced or by whether ST segments become elevated or depressed during spontaneous angina (Fig. 3). In addition, patients with main left coronary artery stenosis did not differ from other patients with the same jeopardy

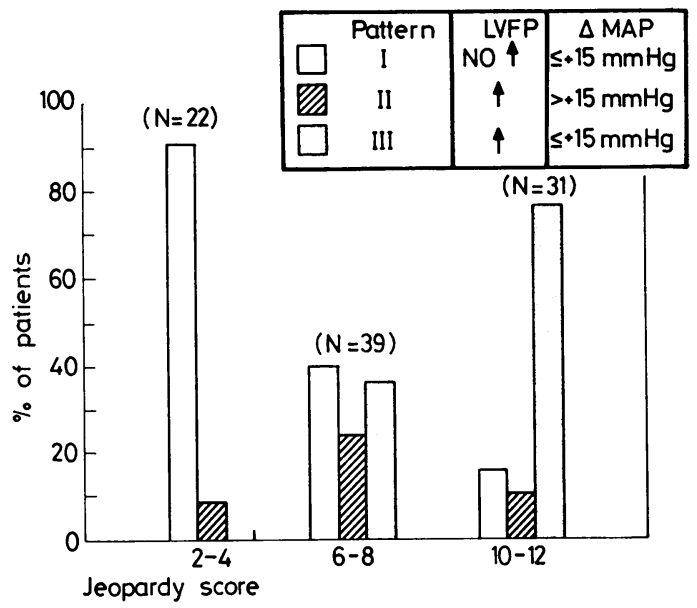

Fig. 2 The percentage of patients in jeopardy score subgroups 2 and 4, 6 and 8 , and 10 and 12 in whom each of the 3 haemodynamic patterns of left ventricular ischaemia developed. Spontaneous angina and pacing study patients are combined. Left ventricular filling pressure $(L V F P) \uparrow$ refers to a rise in LVEDP of more than $7 \mathrm{mmHg}$ or a rise in pulmonary wedge pressure of more than $3 \mathrm{mmHg} . \triangle M A P$, change in mean systemic arterial pressure. 
score with regard to the likelihood that a given haemodynamic response would occur (Fig. 3).

Once the jeopardy score is taken into account, the resting ejection fraction does not appear to exert an independent influence on the pattern of haemodynamic response to ischaemia (Fig. 4).

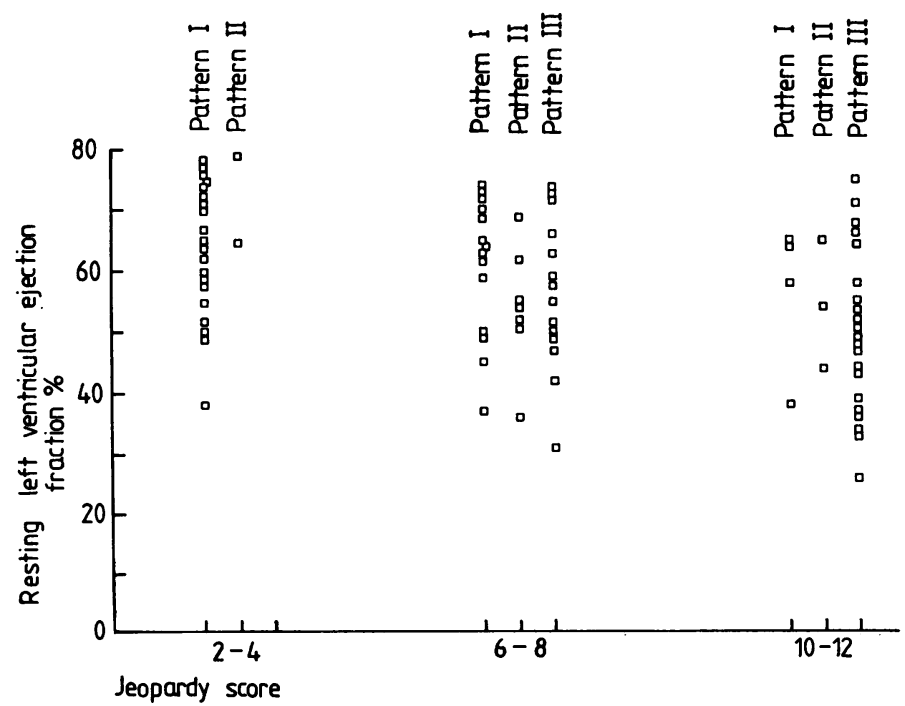

Fig. 4 The pattern of haemodynamic response during ischaemia according to the patients' resting angiographic left ventricular ejection fraction, and coronary angiographic jeopardy score. 
Table 2 Pacing study patients: LVFP, stroke work relation *

\begin{tabular}{|c|c|c|c|c|c|c|c|}
\hline $\begin{array}{l}\text { Feopardy } \\
\text { score }\end{array}$ & $E F+$ & $\begin{array}{l}\text { LVFP change } \\
\text { during pacing }\end{array}$ & $\begin{array}{l}\Delta S V \\
(\%)\end{array}$ & $\begin{array}{l}\triangle M A P \\
(m m H g)\end{array}$ & $\begin{array}{l}\Delta S W \\
\text { (joules) }\end{array}$ & $\begin{array}{l}\text { Decline of } \\
\text { ventricular } \\
\text { function curve }\end{array}$ & $\begin{array}{l}\text { Pattern of } \\
\text { haemodynamic } \\
\text { response } \$\end{array}$ \\
\hline 2 & 0.71 & -6 & -36 & +6 & -0.390 & No & I \\
\hline 2 & 0.71 & -9 & -44 & +2 & $-0 \cdot 183$ & No & I \\
\hline 2 & 0.73 & -10 & -33 & +6 & -0.151 & No & I \\
\hline 2 & 0.72 & -8 & -35 & +3 & -0.204 & No & I \\
\hline 2 & 0.50 & -5 & -47 & +5 & -0.149 & No & I \\
\hline 2 & 0.38 & -9 & -49 & -10 & -0.343 & No & I \\
\hline 2 & 0.65 & +1 & -55 & +22 & -0.413 & Yes & II \\
\hline 4 & 0.60 & -2 & -50 & +5 & -0.724 & No & I \\
\hline 4 & 0.59 & -6 & -39 & +14 & -0.281 & No & I \\
\hline 4 & 0.67 & -8 & -44 & +12 & -0.347 & No & $\vec{I}$ \\
\hline 4 & 0.64 & -11 & -41 & +4 & $-0 \cdot 162$ & No & I \\
\hline 4 & 0.72 & -9 & -29 & +5 & -0.032 & No & I \\
\hline 4 & 0.59 & -24 & -63 & +6 & -0.170 & No & I \\
\hline 4 & 0.79 & +8 & -39 & +18 & -0.366 & Yes & II \\
\hline 6 & 0.37 & -4 & -13 & +13 & +0.170 & No & I \\
\hline 6 & 0.63 & -11 & -58 & +3 & -0.710 & No & I \\
\hline 6 & 0.73 & -9 & -54 & +6 & -0.743 & No & I \\
\hline 6 & 0.62 & -6 & -53 & 0 & -0.481 & No & I \\
\hline 6 & 0.65 & +4 & -55 & +17 & -0.213 & Yes & I \\
\hline 6 & 0.59 & 0 & -53 & +13 & -0.449 & Yes & III \\
\hline 6 & 0.74 & -19 & -70 & -3 & -0.751 & No & III \\
\hline 6 & 0.54 & +10 & -36 & +29 & -0.210 & Yes & II \\
\hline 6 & 0.72 & +5 & -36 & -4 & -0.551 & Yes & III \\
\hline 8 & 0.72 & -11 & -60 & +7 & -0.406 & No & I \\
\hline 8 & 0.63 & -2 & -20 & 0 & -0.211 & No & I \\
\hline 8 & 0.70 & -4 & -37 & +15 & -0.076 & No & I \\
\hline 8 & 0.59 & +1 & +7 & +10 & +0.131 & No & I \\
\hline 8 & 0.69 & -12 & -47 & +15 & -0.531 & No & I \\
\hline 8 & 0.66 & +5 & -35 & +15 & -0.222 & Yes & III \\
\hline 8 & 0.55 & +16 & -52 & +15 & -0.743 & Yes & III \\
\hline 8 & 0.36 & +7 & -24 & +22 & -0.213 & Yes & II \\
\hline 8 & 0.50 & +6 & -29 & +10 & -0.331 & Yes & I \\
\hline 8 & 0.62 & +2 & -28 & +19 & -0.035 & Yes & II \\
\hline 8 & NA & -7 & -42 & +5 & -0.236 & No & III \\
\hline 10 & 0.38 & -8 & -43 & +5 & -0.203 & No & I \\
\hline 10 & 0.44 & +5 & -34 & +22 & -0.053 & Yes & II \\
\hline 10 & 0.66 & +3 & -35 & -1 & -0.221 & Yes & III \\
\hline 12 & 0.64 & -1 & -24 & +9 & 0 & No & I \\
\hline 12 & 0.65 & -6 & -55 & +16 & -0.265 & No & II \\
\hline 12 & 0.53 & +7 & -46 & +15 & -0.287 & Yes & III \\
\hline 12 & $0 \cdot 48$ & +10 & -37 & 0 & -0.235 & Yes & III \\
\hline
\end{tabular}

*The change in left ventricular filling pressure (LVFP), stroke volume ( $\triangle S V$ ), mean arterial pressure ( $\triangle M A P)$, and stroke work ( $\Delta S W$ ); measurements at the highest paced rate are compared with baseline (unpaced) values. LVFP was recorded as LVEDP in 40 patients and pulmonary wedge pressure in 1 patient.

†EF, left ventricular ejection fraction (measured at rest).

\pm See text for definition.

SSee text for definition.

NA, not available.

In those patients in whom cardiac output determinations were available (Tables 2 and 3), a decline in the ventricular function curve was demonstrable in only 2 of $24(8 \%)$ with a pattern I response, in 7 of $13(54 \%)$ with a pattern II response, and in 15 of $17(88 \%)$ of those with a pattern III response $(\mathrm{P}<0.01)$.

A linear correlation exists between the change in mean systemic arterial pressure and the change in cardiac output for the spontaneous angina patients (Fig. 5A) and for the pacing study patients (Fig. 5B) who had a pattern II or a pattern III response to ischaemia, though the correlation is less close for the paced patients than for the spontaneous angina patients. That the y-intercepts for the best-fit curves shown in Fig. 5A and 5B are $14.8 \mathrm{mmHg}$ and
$13.7 \mathrm{mmHg}$, respectively, rather than zero, suggests that a rise in systemic vascular resistance accompanied left ventricular ischaemia in these patients. In the patients who had a pattern I response to ischaemia (all in whom cardiac output determinations were available were paced patients), the change in mean systemic arterial pressure and the change in cardiac output were unrelated (Fig. $5 \mathrm{C})$.

\section{Discussion}

This study shows that the haemodynamic changes occurring in patients with coronary artery disease during rapid atrial pacing or during spontaneous angina may be grouped into three patterns on the 
Table 3 Spontaneous angina: LVFP stroke work relation $\star$

\begin{tabular}{|c|c|c|c|c|c|c|c|}
\hline $\begin{array}{l}\text { Feopardy } \\
\text { score }\end{array}$ & $E F$ & $\begin{array}{l}\Delta S V \\
(\%)\end{array}$ & $\begin{array}{c}\triangle M A P \\
(m m H g)\end{array}$ & $\begin{array}{l}\Delta S W \\
\text { (joules) }\end{array}$ & $\begin{array}{l}\triangle L V F P \\
(m m H g)\end{array}$ & $\begin{array}{l}\text { Decline of } \\
\text { ventricular } \\
\text { function curve } \dagger\end{array}$ & $\begin{array}{l}\text { Pattern of } \\
\text { haemodynamic } \\
\text { response }\end{array}$ \\
\hline $\begin{array}{r}6 \\
6 \\
6 \\
6 \\
8 \\
8 \\
8 \\
8 \\
10 \\
10 \\
10 \\
12 \\
12 \\
12\end{array}$ & $\begin{array}{l}0.55 \\
0.52 \\
\text { NA } \\
0.69 \\
0.54 \\
0.31 \\
0.42 \\
0.58 \\
0.44 \\
0.36 \\
\text { NA } \\
0.33 \\
0.71\end{array}$ & $\begin{array}{l}-9 \\
-7 \\
+12 \\
-16 \\
+23 \\
+4 \\
-15 \\
-20 \\
-14 \\
-39 \\
-36 \\
-25 \\
+7\end{array}$ & $\begin{array}{l}+45 \\
+25 \\
+45 \\
+40 \\
+25 \\
+5 \\
+5 \\
+10 \\
+15 \\
-15 \\
+10 \\
-10 \\
-11\end{array}$ & $\begin{array}{l}+0.276 \\
+0.125 \\
+0.361 \\
+0.212 \\
+0.309 \\
-0.314 \\
-0.088 \\
-0.391 \\
-0.167 \\
-0.187 \\
-0.267 \\
-0.230 \\
-0.117\end{array}$ & $\begin{array}{l}+11 \\
+8 \\
+21 \\
+11 \\
+6 \\
+13 \\
+8 \\
+11 \\
+25 \\
+15 \\
+18 \\
+4 \\
+10\end{array}$ & $\begin{array}{l}\text { No } \\
\text { No } \\
\text { No } \\
\text { No } \\
\text { No } \\
\text { Yes } \\
\text { Yes } \\
\text { Yes } \\
\text { Yes } \\
\text { Yes } \\
\text { Yes } \\
\text { Yes } \\
\text { Yes }\end{array}$ & $\begin{array}{l}\text { II } \\
\text { II } \\
\text { II } \\
\text { II } \\
\text { II } \\
\text { III } \\
\text { III } \\
\text { III } \\
\text { III } \\
\text { III } \\
\text { III } \\
\text { III } \\
\text { III }\end{array}$ \\
\hline
\end{tabular}

${ }^{\star A}$ A comparison of haemodynamic measurements that were recorded before and during angina. $\triangle S V, \triangle M A P, \triangle S W$, and $\triangle L V F P$ refer to changes in stroke volume, mean arterial pressure, stroke work, and left ventricular filling pressure occurring during angina. Left ventricular filling pressure was recorded as pulmonary wedge pressure in 12 patients and as LVEDP in 1 patient. EF, left ventricular ejection fraction. tDefined as in text. $¥$ Defined as in text. NA, not available.

A. Spontaneous angina: patternII and pattern III patients
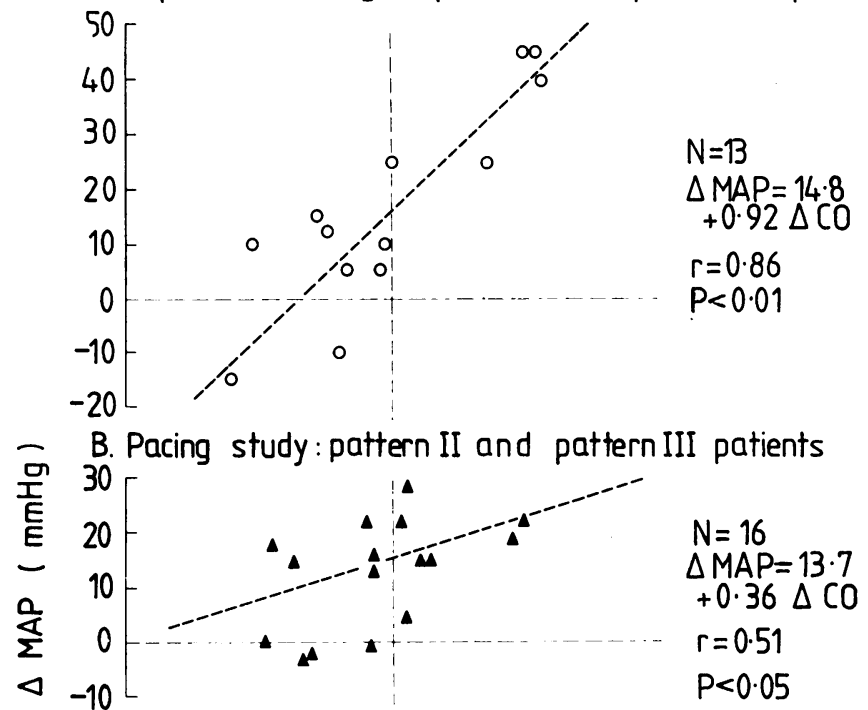

C. Pacing study: pattern I patients

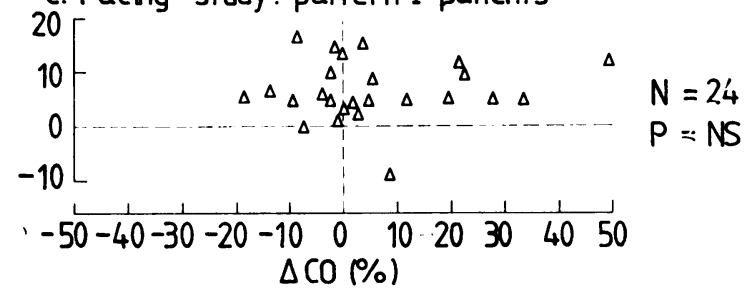

Fig. 5 Patients with coronary artery disease. The relation of the change in the mean systemic arterial pressure $(\triangle M A P)$ to corresponding changes in cardiac output $(\triangle C O)$ occurring during spontaneous angina or during pacing. $(A)$ Spontaneous angina. All patients (13) in whom cardiac output determinations were available had a pattern II or pattern III response to ischaemia. (B) Pacing study patients with a pattern II or pattern III response. (C) Pacing study patients with a pattern I response. 
basis of the change in left ventricular filling pressure and the change in mean systemic arterial pressure. The likelihood of a patient developing any one of these three patterns is strongly related to the extent of coronary artery disease that is present (Fig. 2)a finding that suggests that the haemodynamic response to ischaemia is determined by the fraction of left ventricle that becomes dysfunctional during ischaemia. Thus, if the ischaemic fraction is small, a pattern I response occurs; if the ischaemic fraction is intermediate, a pattern II response occurs; and if the ischaemic fraction is large, a pattern III response occurs. Two other observations support such a hypothesis. First, whether ischaemicinduced depression of the ventricular function curve could be demonstrated depended on the pattern of haemodynamic response. Second, within a particular jeopardy score subgroup a given pattern of response could occur in patients with resting leftventricular ejection fractions that differed over a wide range; therefore, the extent of preischaemic left ventricular dysfunction, in itself, cannot explain the haemodynamic response to ischaemia. The results of the present study do not allow us to say whether the term ischaemic fraction of the left ventricle should refer to the total amount of ventricle that is dysfunctional during ischaemia, that is, the sum of chronically dysfunctional and acutely dysfunctional areas, or only to that portion of the ventricle that has become dysfunctional acutely. It is clear that in some patients at least, namely in those who have a normal resting left ventricular ejection fraction, that the ischaemic fraction is composed totally of areas that have been dysfunctional acutely.

Goldschlager et al. (1970), Saltups et al. (1971), and Barry et al. (1976) also found that the proportion of patients having rises in left ventricular filling pressure during stress (exercise) increased as the extent of coronary artery disease increased, but in the first and second studies a minority of patients had angina, and no ventriculographic data were reported that would allow separation of the effects of acute ischaemia from those of chronic left ventricular functional impairment. Cannom et al. (1974) and Roy et al. (1975) interpreted the findings of their studies(spontaneous angina and pacing-induced angina, respectively) as showing no relation between the extent of coronary artery disease and haemodynamic changes occurring during ischaemia, but both studies included relatively small numbers of patients.

The results of our study imply that an interaction of a number of factors surrounds an episode of left ventricular ischaemia. The rise in the mean systemic arterial pressure in patients with a pattern II haemodynamic response is, in part, the result of an increase in systemic arteriolar resistance. In addition, venomotor tone may also increase during ischaemia in pattern II patients, causing an increase in venous return, since cardiac output rises (Fig. 5), and, at least in some patients with spontaneous angina, the rise in cardiac output is accompanied by a rise in stroke volume. An alternative explanation for the rise in stroke volume would be an increase in the left ventricular ejection fraction, but that seems unlikely, since the ventricle is ischaemic. Patients in whom the cardiac output falls during ischaemia (pattern III response) (Fig. 5) are almost certainly having an ischaemia-induced decline in left ventricular ejection fraction to account for the rise in left ventricular filling pressure. Angiographic evidence for a fall in ejection fraction in some patients during angina has been provided by Sharma et al. (1976). In pattern II patients it remains to be elucidated whether a change in left ventricular compliance (McLaurin et al., 1973; Barry et al., 1974), a change in ejection fraction, or both (Mann et al., 1977) contribute to the rise in left ventricular filling pressure, in addition to a probable increase in venous return.

The results of the present study conflict with the view of Guazzi and co-workers (1975) that haemodynamic alterations in patients with Prinzmetal's variant angina differ from haemodynamic alterations in patients with ST segment depression during angina. When the extent of coronary artery disease is taken into account, the 7 patients in our study with ST segment elevation during spontaneous angina had haemodynamic behaviour that was similar to that of patients with ST segment depression.

Several potential problems in the interpretation of our data warrant discussion. First, rapid atrial pacing data involve measurements that may appear arbitrary. We measured the change in left ventricular filling pressure produced by pacing at the offset of pacing (Khaja et al., 1970) (except for the assessment of a shift in the ventricular function curve - see Methods), but we measured the change in mean systemic arterial pressure during pacing, so that the relation between the change in mean systemic arterial pressure and the change in cardiac output could be studied. The value of measuring the change in ventricular filling pressure and the change in mean systemic arterial pressure in this manner is supported by the results. As judged by the relation of the pattern of haemodynamic change to the jeopardy score, ischaemia was equally well detected in pacing patients and in spontaneous angina patients. In addition, the change in mean systemic arterial pressure and the change in the cardiac output were related linearly in both paced and 
spontaneous angina patients who had a pattern II or pattern III response, which supports the view that a rise in mean systemic arterial pressure during pacing is of physiological significance and not simply an artefact of rapid pacing. That the correlation of the change in mean systemic arterial pressure with the change in cardiac output was closer in patients with spontaneous angina than in those with pacing-induced ischaemia is not surprising. The rapid pacing rates in themselves have some effect on mean systemic arterial pressure (the average change in mean systemic arterial pressure in the 5 control patients was $+7 \mathrm{mmHg}$ for example), and a wide range of heart rates is present in the pacing study population.

Second, only a single ischaemic episode per patient was studied. If the degree of ischaemia varied from episode to episode, the apparent relation of the consequences of ischaemia to the angiographic extent of coronary artery disease might thereby be affected. Our interpretation of the data, however, does not depend on the assumption that recurrent episodes of ischaemia in a given patient are identical, but only on the assumption that within an angiographic subpopulation are patients who reveal the range of possible degrees of ischaemia for the extent of coronary artery disease that is present.

Third, other factors, not specifically measured in the present study, might affect the haemodynamic consequences of ischaemia or the relation of ischaemia to the coronary arteriogram. For example, haemodynamic manifestations of ischaemia may vary with time during an ischaemic episode in some patients (Guazzi et al., 1975). Mitral regurgitation might develop (Brody and Criley, 1970; Bauman and Sutton, 1975). Many of our patients were on antianginal drugs, and some on intraaortic counterpulsation-interventions that might affect responses to ischaemia. The jeopardy score does not differentiate total from subtotal coronary artery obstruction, or take collateral vessels into account. And interobserver variability exists in the assessment of the coronary arteriogram (Zir et al., 1976). Nevertheless, though any of these factors might explain differences among individual patients within a jeopardy score subgroup, none of them would affect observed differences between angiographic subpopulations unless they were represented only in some subpopulations and not in others, or unless their occurrence depended on the fraction of left ventricle that was ischaemic. The proportion of patients taking antianginal drugs did not differ among jeopardy score subgroups, and only a few patients had angina while undergoing intra-aortic counterpulsation.

Fourth, in the application of these data to the individual patient, the possible pitfall of over reliance on absolute cutoffs for 'significant' changes should be noted. The threshold values we employed proved useful for investigative purposes, but these were largely arbitrary and might prove misleading for occasional patients who have a 'borderline' change in left ventricular filling pressure, mean systemic arterial pressure, or both. That the use of absolute threshold values for judging significant pressure changes can cause occasional misclassification of the haemodynamic pattern is suggested by our finding that two pattern I patients had a decline in their ventricular function curve during ischaemia, and 2 pattern III patients did not.

Finally, our proposal that the haemodynamic response to ischaemia is determined by the ischaemic fraction of the left ventricle is based primarily upon the distribution of haemodynamic patterns among angiographic subpopulations; hence, it is inferential in nature. Its confirmation will await means whereby the ischaemic fraction of the ventricle can be directly visualised. Whether done by haemodynamic or by other means, however, estimation of the fraction of left ventricle that is ischaemic during angina will almost certainly prove important to our understanding of the natural history of coronary artery disease and whether it is affected by revascularisation procedures or by medical treatment. Such an estimate may also prove important in decisions regarding the urgency of angiographic and surgical procedures for patients having unstable angina in the setting of the coronary care unit.

\section{References}

Barry, W. H., Brooker, J. Z., Alderman, E. L., and Harrison, D. C. (1974). Changes in diastolic stiffness and tone of the left ventricle during angina pectoris. Circulation, 49, 255-263.

Barry, W. H., Pfeifer, J. F., Lipton, M. J., Tilkian, A. G., and Hultgren, H. N. (1976). Effects of coronary artery bypass grafting on resting and exercise hemodynamics in patients with stable angina pectoris: a prospective randomized study. American fournal of Cardiology, 37, 823-830.

Bauman, D. J., and Sutton, R. B. (1975). Unusual hemodynamic response during exercise induced angina pectoris. Chest, 68, 365-367.

Brody, W., and Criley, J. M. (1970). Intermittent severe mitral regurgitation. Hemodynamic studies in patients with recurrent acute left-sided heart failure. New England fournal of Medicine, 283, 673-676.

Cannom, D. S. Harrison, D. C., and Schroeder, J. S. (1974). Hemodynamic observations in patients with unstable angina pectoris. American fournal of Cardiology, 33, 17-22.

Cohen, L. S., Elliott, W. C., Rolett, E. L., and Gorlin, R. (1965). Hemodynamic studies during angina pectoris. Circulation, 31, 409-416.

Dash, H., Johnson, R. A., Dinsmore, R. E., and Harthorne, J. W. (1977). Cardiomyopathic syndrome due to coronary artery disease. I. Relation to angiographic extent of coronary 
artery disease and to remote myocardial infarction. British Heart fournal, 39, 733-739.

Goldschlager, N., Sakai, F. J., Cohn, K. E., and Selzer, A. (1970). Hemodynamic abnormalities in patients with coronary artery disease and their relationship to intermittent ischemic episodes. American Heart fournal, 80, 610-618.

Guazzi, M., Polese, A., Fiorentini, C., Magrini, R., Olivari, M. T., and Bartorelli, C. (1975). Left and right heart haemodynamics during spontaneous angina pectoris. Comparison between angina with ST segment depression and angina with ST segment elevation. British Heart Fournal, 37, 401-413.

Kasser, I. S., and Kennedy, J. W. (1969). Measurement of left ventricular volumes in man by single-plane cineangiocardiography. Investigative Radiology, 4, 83-90.

Khaja, F., Parker, J. O., Ledwich, R. J., West, R. O., and Armstrong, P. W. (1970). Assessment of ventricular function in coronary artery disease by means of atrial pacing and exercise. American fournal of Cardiology, 26, 107-116.

Lecerof, H. (1974). Central haemodynamics during spontaneous angina pectoris. British Heart fournal, 36, 10871091.

Littler, W. A., Honour, A. J., Sleight, P., and Stott, F. D. (1973). Direct arterial pressure and the electrocardiogram in unrestricted patients with angina pectoris. Circulation, 48, 125-134.

McLaurin, L. P., Rolett, E. L., and Grossman, W. (1973). Impaired left ventricular relaxation during pacing-induced ischemia. American fournal of Cardiology, 32, 751-757.

Mann, T., Brodie, B. R., Grossman, W., and McLaurin, L. P. (1977). Effect of angina on the left ventricular diastolic pressure-volume relationships. Circulation, 55, 761-766.

Müller, O., and Rørvik, K. (1958). Haemodynamic consequences of coronary heart disease with observations during anginal pain and on the effect of nitroglycerin. British Heart fournal, 20, 302-310.

Parker, J. O., Ledwich, J. R., West, R. O., and Case, R. B. (1969). Reversible cardiac failure during angina pectoris. Hemodynamic effects of atrial pacing in coronary artery disease. Circulation, 39, 745-757.

Roughgarden, J. W., and Newman, E. V. (1966). Circulatory changes during the pain of angina pectoris. American fournal of Medicine, 41, 935-946.

Roy, P. R., Sowton, G. E., and Di Luzio, V. (1975). Haemodynamic events in right and left ventricle during angina induced by atrial pacing. British Heart fournal, 37, 520-524.

Saltups, A., McCallister, B. D., Hallerman, F. J., Wallace, R. B., Smith, R. E., and Frye, R. L. (1971). Left ventricular hemodynamics in patients with coronary artery disease and in normal subjects. Correlations with the extent of coronary artery lesions and the electrocardiogram. American Fournal of Medicine, 50, 8-19.

Sharma, B., Goodwin, J. F., Raphael, M. J., Steiner, R. E., Rainbow, R. G., and Taylor, S. H. (1976). Left ventricular angiography on exercise. A new method of assessing left ventricular function in ischaemic heart disease. British Heart fournal, 38, 59-70.

Thomson, P. D., and Kelemen, M. H. (1975). Hypotension accompanying the onset of exertional angina. A sign of severe compromise of left ventricular blood supply. Circulation, 52, 28-32.

Zir, L. M., Miller, S. W., Dinsmore, R. E., Gilbert, J. P., and Harthorne, J. W. (1976). Interobserver variability in coronary angiography. Circulation, 53, 627-732.

Requests for reprints to Dr Robert Arnold Johnson, Cardiac Unit, Massachusetts General Hospital, Boston, Massachusetts 02114, USA. 